\title{
Impact of Social Determinants of Health on Patients with Complex Diabetes Who Are Served by National Safety-Net Health Centers
}

\author{
Vivian Li, MS, Mary Ann McBurnie, PhD, Melissa Simon, MD, MPH, \\ Phil Crawford, MS, Michael Leo, PhD, Fred Rachman, MD, Erika Cottrell, PhD, MPP, \\ Lydia Dant, MPH, Mary Oneha, APRN, PhD, and Rosy Chang Weir, PhD
}

Objective: Recent research demonstrates an increased need to understand the contribution of social determinants of health (SDHs) in shaping an individual's health status and outcomes. We studied patients with diabetes in safety-net centers and evaluated associations of their disease complexity, demographic characteristics, comorbidities, insurance status, and primary language with their HbA1c level over time.

Methods: Adult patients with diabetes with at least 3 distinct primary care visits between January 1 , 2006, and December 31, 2013, were identified in the CHARN data warehouse. These patients were categorized into 4 groups: those without a diagnosis of cardiovascular disease (CVD) or depression; those with CVD but not depression; those with depression but not CVD; and those with CVD and depression. Charlson score; demographic characteristics such as age, sex, and race/ethnicity; and SDHs such as primary language and insurance status were used as predictors. The outcome measure was HbA1c. Hypothesis testing was conducted using 3-level hierarchical linear models.

Results: Baseline HbA1c differed significantly across the 4 diabetes groups and by race/ethnicity. The amount of HbA1c change over time differed by insurance status. Patients who were continuously insured tended to have lower baseline HbA1c and a smaller increase. Chinese-speaking patients tended to have lower baseline HbA1c but a larger increase over time compared with English speakers. There were various unexpected associations: compared with the diabetes-only group, mean HbA1c tended to be lower among the other more complex groups at baseline; women tended to have lower measures at baseline; older age and higher Charlson scores were associated with lower HbA1c.

Conclusions: There is still unexplained variability relating to both baseline HbA1c values and change over time in the model. SDHs, such as insurance status and primary language, are associated with HbA1c, and results suggest that these relationships vary with disease status among patients with diabetes in safety-net centers. It is important to recognize that there are complex relationships among demographic and SDH measures in complex patients, and there is work to be done in correctly modeling and understanding these relationships. We also recommend prioritizing the collection of SDH and enabling services data for safety-net patients that would be instrumental in conducting a more comprehensive study. (J Am Board Fam Med 2016;29:356-370.)

Keywords: Community Health Centers, Insurance, Safety-Net Providers, Social Determinants of Health

Social determinants of health (SDHs) contribute to disparities in health and a higher prevalence of health-related problems, particularly for medically

This article was externally peer reviewed.

Submitted 20 July 2015; revised 2 March 2016; accepted 8 March 2016.

From the Association of Asian Pacific Community Health Organizations, San Leandro CA (VL, RCW); Kaiser Permanente Center for Health Research, Portland OR (MAB, PC, ML); Northwestern University, Feinberg School of Medicine, Chicago IL (MS); Alliance of Chicago Community underserved populations. The World Health Organization Commission on Social Determinants of Health defines SDHs as "the structural determinants and conditions of daily life responsible for a

Health Services, Chicago IL (FR); OCHIN, Inc., Portland OR (EC); The Fenway Institute, Boston, MA (LD); and the Waimanalo Health Center, Waimanalo, HI (MO).

Funding: This Study was supported by grant no. HHSH250201400001C from the Health Resources and Services Administration.

Conflict of interest: none declared. 
major part of health inequities between and within countries."1 SDHs play a powerful role in shaping health across a wide range of health indicators, settings, and populations. ${ }^{1-5}$ Traditional medical care is not the only influence on health, and the effects of medical care may be more limited than commonly thought, particularly in determining who becomes sick or injured. ${ }^{3-7}$ Interest in studying and describing SDHs has increased over the past few decades, ${ }^{8-10}$ and it is clear that SDHs are associated with suboptimal health status or poor health-related outcomes, ${ }^{11}$ such as higher rates of mental disorders and medical conditions. ${ }^{12}$ In a meta-analysis conducted by Lorant and colleagues, ${ }^{13}$ people with a low socioeconomic status were 1.8 times more likely to report being depressed than were people with higher status. Lett et $\mathrm{al}^{14}$ also found that low social support was associated with a 1.5- to 2-times increased the risk of developing coronary heart disease or experiencing adverse outcomes associated with coronary heart disease.

Community health centers (CHCs) are the health and medical homes for over 22 million people in the United States, primarily populations that have a disproportionately low income (93\%), are uninsured (35\%), or have limited English proficiency (23\%). ${ }^{15}$ Studying these populations provides a unique opportunity to understand and characterize the effect of SDHs on health care use and health outcomes, and to better identify the factors that increase the risk of poor health. Typically, CHC patients are poorer, more racially and ethnically diverse, more likely to report being in fair or poor health, and more likely to be unemployed and uninsured than the broader low-income population. ${ }^{16}$ For example, the rate of having diabetes mellitus (DM) or borderline DM is $19.2 \%$ among the CHC population versus $12.0 \%$ among the general lowincome US population; the rate of having $\geq 2$ health conditions (DM, asthma, hypertension, a liver condition, coronary heart disease, and emphysema) in a lifetime is $25.4 \%$ for CHC patients but $16.6 \%$ for the general low-income US population; and the rate of being uninsured is $34.4 \%$

Corresponding author: Vivian Li, MS, Association of Asian Pacific Community Health Organizations, 101 Callan Avenue, Suite 400, San Leandro CA 94577 (E-mail: vli@aapcho.org). for CHC patients versus $12.6 \%$ for the general low-income US population. ${ }^{16}$ Moreover, a large proportion of patients who receive care at $\mathrm{CHCs}$ have complex health needs, including multiple chronic diseases and behavioral health conditions (eg, depression or substance abuse). ${ }^{17}$ Among the broader US population, those with behavioral health disorders have significantly higher rates of having comorbid medical conditions, ${ }^{12}$ a higher incidence of $\mathrm{DM},{ }^{12}$ worse $\mathrm{DM}$ outcomes over time, ${ }^{18}$ and a higher risk of death from DMrelated complications. ${ }^{19}$ Moreover, the use of nonpreventive medical services (eg, in an emergency department, hospitalization, 30-day readmission, avoidable hospitalization) is significantly higher among patients with behavioral health conditions than those without. ${ }^{20,21}$ Thus it is important to understand the relationship between behavioral health, medical comorbidities, and SDHs in CHC settings to understand how best to serve these high-risk populations.

The Community Health Applied Research Network (CHARN), which was established in 2010, provides an opportunity to examine some of the relationships between behavioral health, medical comorbidities, and SDHs. CHARN consists of 4 safety-net research nodes, each of which has affiliated CHCs and an academic or research partner. Each node includes $\geq 3 \mathrm{CHCs}$ (17 total). The participating $\mathrm{CHCs}$ are located in 9 states across the country, and all have provided standardized data to the centralized CHARN Data Warehouse (CDW). The 4 nodes are Alliance of Chicago Community Health Services (Alliance; Chicago, IL); the Association of Asian Pacific Community Health Organizations (AAPCHO; San Leandro, CA); Fenway Health (Fenway; Boston, MA); and OCHIN (formerly the Oregon Community Health Information Network but shortened to OCHIN when other states joined; Portland, OR). ${ }^{22}$ Figure 1 shows the structure of CHARN.

For this retrospective study, we identified diabetic patients in the CDW and determined whether they also had a diagnosis of cardiovascular disease (CVD), depression, or both. DM was chosen as the focus because of the potential complexity of the disease and its treatment (ie, with or without comorbidities). In addition, DM is well documented in electronic health records (EHRs), as is its outcome measure, glycohemoglobin (HbA1c) level, which enabled us to use EHR data across 
Figure 1. Structure of the Community Health Applied Research Network (CHARN). ${ }^{22}$ *0verall governance of the network is the responsibility of the CHARN Steering Committee (SC). The SC is responsible for approving final decisions, establishing subcommittees, affirming their charters, and appointing subcommittee chairs. ${ }^{\dagger}$ Asian Health Services, CA; Charles B. Wang Community Health Center, NY; Waianae Coast Comprehensive Health Center, HI; Waimanalo Health Center, HI. "Erie Family Health Center, IL; Glide Health Services, CA; Heartland Health Outreach, IL; Howard Brown Health Center, IL; Near North, IL; North Country Health Care, AZ; PCC Community

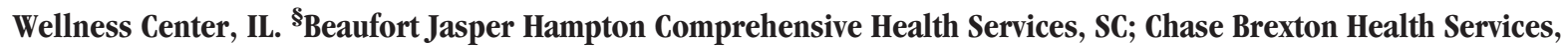
MD; Fenway Health, MA. "Multnomah County Health Department, OR; Richmond Clinic, OR; Open Door Community Health Center, CA; Virginia Garcia Memorial Health Center, OR. AAPCHO, Association of Asian Pacific Community Health Organizations; DCC, Data Coordinating Center at the Kaiser Permanente Center for Health Research, Portland, Oregon; UCLA, University of California, Los Angeles.

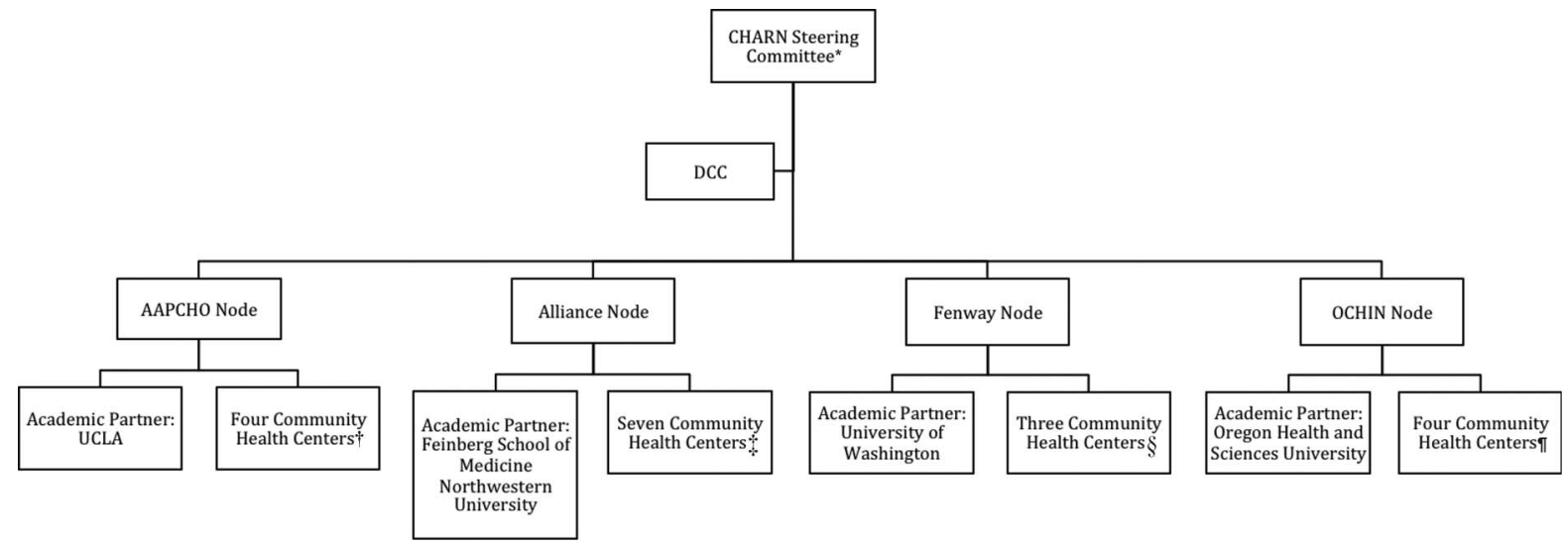

CHARN CHCs from the centralized CDW. Because $19 \%$ of health center patients across the nation have DM or prediabetes, ${ }^{16}$ it is also important to learn more about these patients to better allocate limited CHC resources to improve health outcomes. CVD also poses a significant health burden in vulnerable populations, and depression is a common mental condition among CHC patients that is closely related to outcomes of other medical conditions. ${ }^{12}$ In this article we evaluate the association between DM disease status and change in HbAlc level over time, and we test whether adverse HbA1c trajectories are associated with SDH factors. We treated 2 SDHs-primary language and insurance continuity - as potential barriers to health care for CHC patients. ${ }^{23-27}$ Language barriers in the health care setting can lead to a delay or denial of services, issues with medication management, and underuse of preventive services. ${ }^{23-25}$ Compared with insured patients, patients without insurance tend to have worse access to care, less continuity of care, more unmet needs, and worse outcomes. ${ }^{26,27}$ The CDW includes patient-level demographic information, insurance coverage status, primary language, and disease status. We hypothesized that diabetic patients with more complex health profiles (ie, pa- tients with comorbidities) experience more adverse HbA1c trajectories (change over time) than less complex patients and that these trajectories are associated with demographic and SDH characteristics.

\section{Methods \\ Study Population}

We retrospectively identified nonpregnant patients in the CDW who had at least 1 primary care visit per year for 3 consecutive years and who were aged $\geq 18$ years on December 31, 2009. Of these, patients with at least 2 visits with DM-related International Classification of Diseases, 9th Revision (ICD-9) codes were considered to have $\mathrm{DM}^{28}$; the DM index date was defined as the date of the second visit at which DM was identified.

\section{Data Source}

We used version 2 (November 2014) of the CDW, which contains EHR data on nearly 1 million patients who made $\geq 1$ primary care visits to any of CHARN's 17 CHCs between January 1, 2006, and December 31, 2013. The CDW is housed within the CHARN data coordinating center and is stored 
behind a secure firewall on an SQL Server (R2012) using industry-standard encryption at the Kaiser Permanente Center for Health Research. The research nodes upload the EHR-based CHC limited data sets to the secure website at the data coordinating center from their local data warehouses, which conform to a standardized SQL relational database schema. ${ }^{29}$ All CHARN studies, including this one, have received institutional review board approval.

\section{Measures}

All information was retrospectively collected from the CDW. Self-reported measures included age calculated as of 2013, sex, race/ethnicity, and primary language. Insurance status was determined based on documented coverage at each encounter and was coded according to whether patients had been continuously insured across all encounters, had gaps in insurance coverage (ie, a lapse of insurance coverage of $>30$ days), or had been continuously uninsured. To assess health care use, we calculated the average annual number of visits. We evaluated primary language and insurance status as our SDH factors.

To adjust our analyses for patients' overall comorbidity burden, we computed the Charlson index score based on the ICD-9 codes documented in the EHR during a 12-month period (between 10 months before and 2 months after the index date). The Charlson index was designed to estimate the long-term prognosis and lethality of comorbid patients and is based on a point-scoring system (from 0 to 40) for the presence of specific associated diseases. Points are accumulated according to the associated diseases and a single point for each 10 years of age for patients older than 40 (in 50 years, 1 point; 60 years, 2 points; etc.). The distinguishing feature and undisputed advantage of the Charlson index is its ability to evaluate a patient's age and determine his or her mortality rate, which in the absence of comorbidity ( 0 points) is $12 \%$, at 1 or 2 points is $26 \%$, at 3 or 4 points is $52 \%$, and at $\geq 5$ points is $85 \%$. In 1992 Deyo et $\mathrm{al}^{30}$ added to this index chronic forms of ischemic cardiac disorder and the stages of chronic cardiac insufficiency.

Diabetic patients were categorized using ICD-9 codes as: without a diagnosis of CVD or depression (DM-only); with only a diagnosis of CVD (DM + CVD); with only a diagnosis of depression $(\mathrm{DM}+\mathrm{DEP})$; or with diagnoses of both CVD and depression (DM + CVD + DEP). CVD or depression diagnosed within 60 days of the DM index date was considered a comorbidity. The outcome measure in this study was change in HbA1c level over time. ICD-9 codes used to define these conditions are listed in Table 1.

After careful discussion, we chose the abovementioned variables to describe the patients' basic demographics, SDHs, and disease status without having to include so many variables that the models would not have enough power. We considered other variables such as homeless status and federal poverty level, but because of the incompleteness of the data in CDW version 2.2, we were not able to include them in the study.

\section{Data Analysis}

Population characteristics are described using means and standard deviations (SDs), percentages, and counts. Significance tests for differences in patient characteristics between disease groups were not performed because we did not have hypotheses of interest related to these comparisons. Observed differences are described for selected characteristics to orient the reader to the population studied. The hypothesis was tested using 3-level hierarchical linear models in a growth curve framework ${ }^{31-33}$ to account for correlated observations of repeated measures within patients and for patients within CHCs. The first level of the model included time (years from index diagnosis) as a predictor, thus modeling the within-person variation. The second level included dummy variables for the DM groupings (referent: DMonly group) and for the other categorical (also dummy coded) and continuous person-level predictors for both the intercept and slope for time random effects. Personlevel predictors included age, Charlson index score, sex, race/ethnicity, insurance status, primary language, and average number of annual primary care visits. The third level of the model was the $\mathrm{CHC}$ level and included node (dummy coded) as a predictor of the level-2 intercept and slope random effects. The interpretation of a significant coefficient for a given nonreferent group (ie, DM $+\mathrm{CVD}, \mathrm{DM}+\mathrm{DEP}$, or DM + CVD + DEP) on the intercept indicates that the nonreferent group differs from the referent group (DM only) on HbAlc level at the time of the DM diagnosis, whereas a significant coefficient for the slope of time indicates that there are different trajectories across time. These interpretations assume that all other variables are held constant. We 
Table 1. International Classification of Diseases, 9th Revision Codes of Diabetes, Cardiovascular Disease, and Depression

\begin{tabular}{|c|c|c|}
\hline Diagnosed Condition & Primary Care Visit/Problem List & ICD-9 Codes \\
\hline \multirow[t]{10}{*}{ Diabetes } & Diabetes mellitus & 250.xx \\
\hline & Polyneuropathy in diabetes & 357.2 \\
\hline & Diabetic retinopathy & 362.0 \\
\hline & Background diabetic retinopathy & 362.01 \\
\hline & Proliferative diabetic retinopathy & 362.02 \\
\hline & Nonproliferative diabetic retinopathy NOS & 362.03 \\
\hline & Mild nonproliferative diabetic retinopathy & 362.04 \\
\hline & Moderate nonproliferative diabetic retinopathy & 362.05 \\
\hline & Severe nonproliferative diabetic retinopathy & 362.06 \\
\hline & Diabetic macular edema & 362.07 \\
\hline \multirow{4}{*}{$\begin{array}{l}\text { Cardiovascular } \\
\text { Disease }\end{array}$} & Myocardial infarction & 410.x, 412.x \\
\hline & Congestive heart failure & 428.x \\
\hline & Peripheral vascular disease & $443.9,441 . x, 785.4, V 43.4$ \\
\hline & Cerebrovascular disease & 430.x to $438 . x$ \\
\hline \multirow[t]{10}{*}{ Depression } & Major depressive affective disorder, single episode & $296.2 x$ \\
\hline & Major depressive affective disorder, recurrent episode & $296.3 x$ \\
\hline & Atypical depressive disorder & 296.82 \\
\hline & Depressive type psychosis & 298.0 \\
\hline & Dysthymic disorder & 300.4 \\
\hline & Chronic depressive personality disorder & 301.12 \\
\hline & Adjustment disorder with depressed mood & 309.0 \\
\hline & Prolonged depressive reaction & 309.1 \\
\hline & Adjustment disorder with mixed anxiety and depressed mood & 309.28 \\
\hline & Depressive disorder, not elsewhere classified & 311 \\
\hline
\end{tabular}

ICD-9, International Classification of Diseases, 9th Revision; NOS, not otherwise specified.

assessed interactions with DM status for the SDH measures insurance status and primary language.

We modeled all available HbA1c values collected from patients from their index date through 2013. Models estimated index and slope coefficients $(\beta)$ corresponding to node and to each of the person-level measures described above. Because of the complexity of this base model, we used separate models to examine the interaction effects between DM status and each individual covariate. We probed significant interactions by graphing the simple-effects equations to determine the nature of the interaction. Linear contrasts were performed to obtain overall $P$ values for variables with $>2$ categories. Associations were considered statistically significant at the level of $P \leq .05$.

\section{Results}

\section{Population Characteristics}

A total of 114,845 patients in the CDW met the age and health care visit criteria for our study. Of these, 17,360 (15.1\%) had been diagnosed with
DM. Compared with patients who had not been diagnosed with DM, patients with DM were older (mean, 59.4 years [SD, 13.7 years] vs 47 years [15.7 years]). Patients with DM were also more likely to be male $(42.8 \%$ vs $34.8 \%)$ and more likely to be non-Hispanic Asian American, Native Hawaiian, or other Pacific Islander (42.9\% vs $35.7 \%$ ) (Table 2). In addition, more patients with DM than those without were insured through Medicare $(13.4 \%$ vs $5.6 \%)$ and fewer had private insurance $(4.2 \%$ vs $11.7 \%$ ) (data not shown).

Among the 17,360 patients who had been diagnosed with DM, 13,790 (79.4\%) had DM only, 817 (4.7\%) had DM + CVD, 2,495 (14.3\%) had DM + DEP, and 258 (1.5\%) had DM + CVD + DEP (Table 3). The mean (SD) age at the index date for each group was 54.7 (13.4), 61.9 (12.5), 50.7 (12.2), and 58.2 years (10.7 years), respectively. The 2 groups of patients with depression (DM + DEP or $\mathrm{DM}+\mathrm{CVD}+\mathrm{DEP})$ had a noticeably higher percentages of women and non-Hispanic whites than the groups with DM only or DM + CVD, 
Table 2. Characteristics of Adult Community Health Applied Research Network Patients with at Least One Primary Care Visit per Year, for at Least 3 Consecutive Years, between January 1, 2006, and December 31, $2013(\mathrm{~N}=114,845)$

\begin{tabular}{|c|c|c|c|c|c|c|}
\hline & \multicolumn{2}{|c|}{$\begin{array}{l}\text { Patients with } \\
\text { Diabetes }\end{array}$} & \multicolumn{2}{|c|}{$\begin{array}{l}\text { Patients without } \\
\text { Diabetes }\end{array}$} & \multicolumn{2}{|c|}{ Total } \\
\hline & $\mathrm{n}$ & $\mathrm{Col} \%$ & $\mathrm{n}$ & $\mathrm{Col} \%$ & $\mathrm{n}$ & $\mathrm{Col} \%$ \\
\hline \multicolumn{7}{|l|}{ Sex } \\
\hline Male & 7,426 & 42.8 & 33,943 & 34.8 & 41,369 & 36.0 \\
\hline Female & 9,914 & 57.1 & 63,107 & 64.7 & 73,021 & 63.6 \\
\hline Transgender & 20 & 0.1 & 430 & 0.4 & 450 & 0.4 \\
\hline Missing or unknown & 0 & 0.0 & 5 & 0.0 & 5 & 0.0 \\
\hline \multicolumn{7}{|l|}{ Race/ethnicity } \\
\hline Hispanic & 3,212 & 18.5 & 17,263 & 17.7 & 20,475 & 17.8 \\
\hline Non-Hispanic white & 4,378 & 25.2 & 29,103 & 29.9 & 33,481 & 29.2 \\
\hline Non-Hispanic black & 1,740 & 10.0 & 11,368 & 11.7 & 13,108 & 11.4 \\
\hline Non-Hispanic Asian or Pacific Islander & 7,444 & 42.9 & 34,802 & 35.7 & 42,246 & 36.8 \\
\hline Other* & 502 & 2.9 & 4,261 & 4.3 & 4,763 & 4.1 \\
\hline Missing or unknown & 84 & 0.5 & 688 & 0.7 & 772 & 0.7 \\
\hline \multicolumn{7}{|l|}{ Primary language } \\
\hline English & 8,284 & 47.7 & 48,877 & 50.1 & 57,161 & 49.8 \\
\hline Spanish & 2,728 & 15.7 & 12,532 & 12.9 & 15,260 & 13.3 \\
\hline Cantonese or Mandarin & 3,891 & 22.4 & 22,090 & 22.7 & 25,981 & 22.7 \\
\hline Other & 1,689 & 9.8 & 6,246 & 6.4 & 7,935 & 6.9 \\
\hline Missing or unknown & 768 & 4.4 & 7,740 & 7.9 & 8,508 & 7.4 \\
\hline
\end{tabular}

*Includes American Indian and multiracial. Col \%, column percentages.

whereas the latter groups had larger percentages of non-Hispanic Asian American, Native Hawaiian, or other Pacific Islander. The DM-only group had the largest percentage of patients whose primary language was not English and the smallest percentage of patients with $\geq 5$ annual visits. The 2 groups with CVD (DM + CVD or DM + CVD + DEP) had larger percentages of patients who were continuously insured (Table 3).

\section{Multilevel Models}

Base Model

Because of missing records for some measures, the sample size was reduced to 14,878 patients from $14 \mathrm{CHCs}$ for the multilevel models. Eight percent of patients were missing $\mathrm{HbA1c}$ levels, $3 \%$ were missing primary language, and $2 \%$ were missing insurance status.

\section{Associations with Index Date}

After adjusting for age, sex, Charlson score, race/ ethnicity, and node, the estimated marginal mean HbA1c level differed significantly across the 4 DM groups at the index date $(P<.001$ overall $)$ (Table 4). Contrary to our hypothesis, compared with the DM-only group, mean HbA1c level tended to be lower for the groups with diagnosed depression $(\mathrm{DM}+\mathrm{DEP}$ and DM + CVD + DEP groups) at the index date. We also found an association between mean HbAlc level and primary language $(P=.009)$, such that Chinesespeaking patients had a lower HbA1c level than did English speakers $(\beta=-0.213 ; P=.028)$. In addition, compared with patients who were continuously insured $(P=.002$ overall), those who were continuously uninsured $(\beta=0.375 ; P=$ $.010)$ or who had gaps in insurance $(\beta=0.133$; $P=.022)$ tended to have higher mean HbA1c levels at the index date (Figure 2A, Table 4). HbA1c level at the index date also varied significantly by race/ethnicity $(P<.001$ overall); non-Hispanic African Americans $(\beta=0.314 ; P=.004)$ and those in the "other" category (including American Indians and those who identified as multiracial; $\beta=0.393 ; P=.009$ ) experiencing higher mean $\mathrm{HbAlc}$ compared with nonHispanic whites. Women tended to have lower measures at the index date than men $(\beta=-0.231 ; P<$ .001). Unexpected index date associations included negative relationships of age $(\beta=-0.014 ; P=.001)$ and Charlson index score $(\beta=-0.091 ; P=.011)$ with $\mathrm{HbA1c}$ level. 
Table 3. Characteristics of Adult Patients with Diabetes in the Community Health Applied Research Network Who Had at Least One Primary Care Visit over at Least 3 Consecutive Years

\begin{tabular}{|c|c|c|c|c|}
\hline & $\begin{array}{c}\text { DM Only } \\
(\mathrm{n}=13,790)\end{array}$ & $\begin{array}{c}\mathrm{DM}+\mathrm{CVD} \\
(\mathrm{n}=817)\end{array}$ & $\begin{array}{l}\mathrm{DM}+\mathrm{DEP} \\
(\mathrm{n}=2,495)\end{array}$ & $\begin{array}{c}\mathrm{DM}+\underset{(\mathrm{n}=258)}{\mathrm{CVD}}+\mathrm{DEP} \\
4\end{array}$ \\
\hline Age in 2013 (years), mean (SD) & $54.7(13.4)$ & $61.9(12.5)$ & $50.7(12.2)$ & $58.2(10.7)$ \\
\hline \multicolumn{5}{|l|}{ Sex } \\
\hline Male & $6156(45)$ & $402(49)$ & $763(31)$ & $105(41)$ \\
\hline Female & $7624(55)$ & $415(51)$ & $1722(69)$ & $153(59)$ \\
\hline Transgender & $10(<1)$ & $0(0)$ & $10(<1)$ & $0<(0)$ \\
\hline Missing/unknown & $0(0)$ & $0(0)$ & $0(0)$ & $0(0)$ \\
\hline \multicolumn{5}{|l|}{ Race/ethnicity } \\
\hline Hispanic & $2682(19)$ & $63(8)$ & $453(18)$ & $14(5)$ \\
\hline Non-Hispanic white & $2912(21)$ & $246(30)$ & $1104(44)$ & $116(45)$ \\
\hline Non-Hispanic black & $1419(10)$ & $90(11)$ & $197(8)$ & $34(13)$ \\
\hline Non-Hispanic Asian/Pacific Islander & $6314(46)$ & $391(48)$ & $656(26)$ & $83(32)$ \\
\hline Other* & $289(2)$ & $13(2)$ & $39(2)$ & $4(2)$ \\
\hline Missing/unknown & $64(1)$ & $7(1)$ & $11(0)$ & $2(1)$ \\
\hline \multicolumn{5}{|l|}{ Primary language } \\
\hline English & $5919(43)$ & $494(61)$ & $1677(67)$ & $194(75)$ \\
\hline Spanish & $2308(17)$ & $49(6)$ & $358(14)$ & $13(5)$ \\
\hline Cantonese/Mandarin & $3514(26)$ & $158(19)$ & $196(8)$ & $23(9)$ \\
\hline Other & $1395(10)$ & $71(9)$ & $203(8)$ & $20(8)$ \\
\hline Missing/unknown & $654(5)$ & $45(6)$ & $61(2)$ & $8(3)$ \\
\hline \multicolumn{5}{|l|}{ Insurance status } \\
\hline Continuously insured & $7656(56)$ & $614(75)$ & $1478(59)$ & $195(76)$ \\
\hline Continuously uninsured & $2174(16)$ & $41(5)$ & $251(10)$ & $7(3)$ \\
\hline Insurance gaps ${ }^{\dagger}$ & $3476(25)$ & $145(18)$ & $747(30)$ & $55(21)$ \\
\hline Missing or unknown & $484(4)$ & $17(2)$ & $19(1)$ & $1(0)$ \\
\hline Charlson index, mean (SD) & $1.2(0.8)$ & $2.4(1.0)$ & $1.5(1.1)$ & $2.6(1.4)$ \\
\hline \multicolumn{5}{|l|}{ Number of annual visits } \\
\hline 1 or 2 & $1775(13)$ & $51(6)$ & $181(7)$ & $12(5)$ \\
\hline 3 or 4 & $4902(36)$ & $207(25)$ & $565(23)$ & $40(16)$ \\
\hline$\geq 5$ & $7113(52)$ & $559(68)$ & $1749(70)$ & $206(80)$ \\
\hline
\end{tabular}

Data are $\mathrm{n}(\%)$ unless otherwise indicated.

*Includes American Indian and multiracial.

${ }^{\dagger}$ Includes a single encounter.

CVD, cardiovascular disease; DEP, depression; DM, diabetes mellitus; SD, standard deviation.

\section{Trajectory Associations}

The trajectory (slope) of the HbA1c level differed by insurance status $(P=.014$ overall) (Table 5). Patients who were continuously uninsured had steeper increasing trajectories than did those who were continuously insured ( $\beta=0.054 ; P=.024)$. Primary language did not reach statistical significance $(P=.052)$, but Chinese-speaking patients had a more positive slope on HbAlc level than did English speakers $(\beta=0.039 ; P=.051)$, meaning that HbA1c level increased more rapidly for Chinese-speaking patients over time (Table 5). Among the adjustor variables, older age was associated with a decreased trajectory of HbA1c level compared with younger patients $(\beta=-0.003 ; P<.001)$. Model results indicated that there is still significant unexplained variability relating to both the index date and trajectories after accounting for the variables in the model.

\section{Interaction Models}

Because of the complexity of the multilevel models, we fit 2 separate interaction models to evaluate potential interactions of insurance status and primary language with DM status. Each interaction term was evaluated separately by adding it to the base model described above. 
Table 4. Intercept Coefficients: Estimated Marginal Mean Differences in Average HbA1c Level at the Index Date*

\begin{tabular}{|c|c|c|c|c|c|}
\hline $\begin{array}{l}\text { Category for Intercept } \\
\text { Differences for Mean } \\
\text { HbAlc }\end{array}$ & Fixed Effects & $\begin{array}{c}\beta \\
\text { Coefficient }\end{array}$ & $\begin{array}{l}\text { SE } \\
(\beta)\end{array}$ & $\begin{array}{c}P \\
\text { Value }\end{array}$ & $\begin{array}{l}\text { Linear Contrast } \\
P \text { Values }\end{array}$ \\
\hline \multirow[t]{4}{*}{ Node } & Grand mean at baseline (intercept) ${ }^{\dagger}$ & 7.768 & 0.172 & $<.001$ & $<.001$ \\
\hline & Mean HbA1c level difference, node 2 vs node 1 & -0.577 & 0.113 & $<.001$ & \\
\hline & Mean HbA1c level difference, node 3 vs node 1 & -0.391 & 0.232 & .123 & \\
\hline & Mean HbA1c level difference, node 4 vs node 1 & -0.387 & 0.083 & $<.001$ & \\
\hline Age (at baseline) & Each additional year of age & -0.014 & 0.002 & .001 & NA \\
\hline Charlson index score & Each additional Charlson index score point & -0.091 & 0.031 & .011 & NA \\
\hline Sex & Female vs male & -0.231 & 0.040 & $<.001$ & NA \\
\hline \multirow[t]{4}{*}{ Race/ethnicity } & Hispanic vs non-Hispanic white & 0.137 & 0.112 & .243 & $<.001$ \\
\hline & Non-Hispanic black vs non-Hispanic white & 0.314 & 0.090 & .004 & \\
\hline & $\begin{array}{l}\text { Non-Hispanic Asian or Pacific Islander vs non- } \\
\text { Hispanic white }\end{array}$ & 0.015 & 0.087 & .865 & \\
\hline & Non-Hispanic other vs non-Hispanic white & 0.393 & 0.128 & .009 & \\
\hline \multirow[t]{2}{*}{ Insurance status } & Continually uninsured vs continually insured & 0.375 & 0.125 & .010 & .002 \\
\hline & Insurance gaps vs continually insured & 0.133 & 0.051 & .022 & \\
\hline \multirow[t]{3}{*}{ Primary language } & Spanish vs English & 0.035 & 0.145 & .812 & .009 \\
\hline & Cantonese or Mandarin vs English & -0.213 & 0.086 & .028 & \\
\hline & Other language vs English & 0.079 & 0.104 & .457 & \\
\hline \multirow[t]{2}{*}{ Health care use $\neq$} & 3 or 4 Visits vs 1 or 2 visits & 0.012 & 0.081 & .889 & .296 \\
\hline & $\geq 5$ Visits vs 1 or 2 visits & 0.092 & 0.101 & .383 & \\
\hline
\end{tabular}

*This multilevel model predicted mean HbA1c level as a function of diabetes status, primary language, and insurance status, adjusting for age, Charlson index score, sex, race/ethnicity, and node.

${ }^{\dagger}$ Assuming all other covariates equal zero.

${ }^{\ddagger}$ Average number of annual primary care visits.

NA, not available; SE, standard error.

We found a statistically significant interaction between insurance status and DM status $(P=.024$ overall): there was a significant uninsured versus insured vector for DM + DEP versus DM-only interaction $(\beta=$ $-0.441 ; P=.008)$. HbAlc at the index date did not differ among patients with DM + DEP between those who were uninsured and those who were insured; however, patients with DM only who were uninsured tended to have higher $\mathrm{HbAlc}$ at the index date compared with those who were insured (Figure 2).

Figure 2. Insurance status. Baseline interaction of HbA1c with insurance status and diabetes status in the diabetes mellitus [DM] + cardiovascular disease [CVD] + depression [DEP] group (A) compared with DM-only group (B). For the DM + CVD + DEP group, baseline HbA1c did not differ among insurance groups, whereas for those with DM only, uninsured patients had higher baseline HbA1c.

A

B
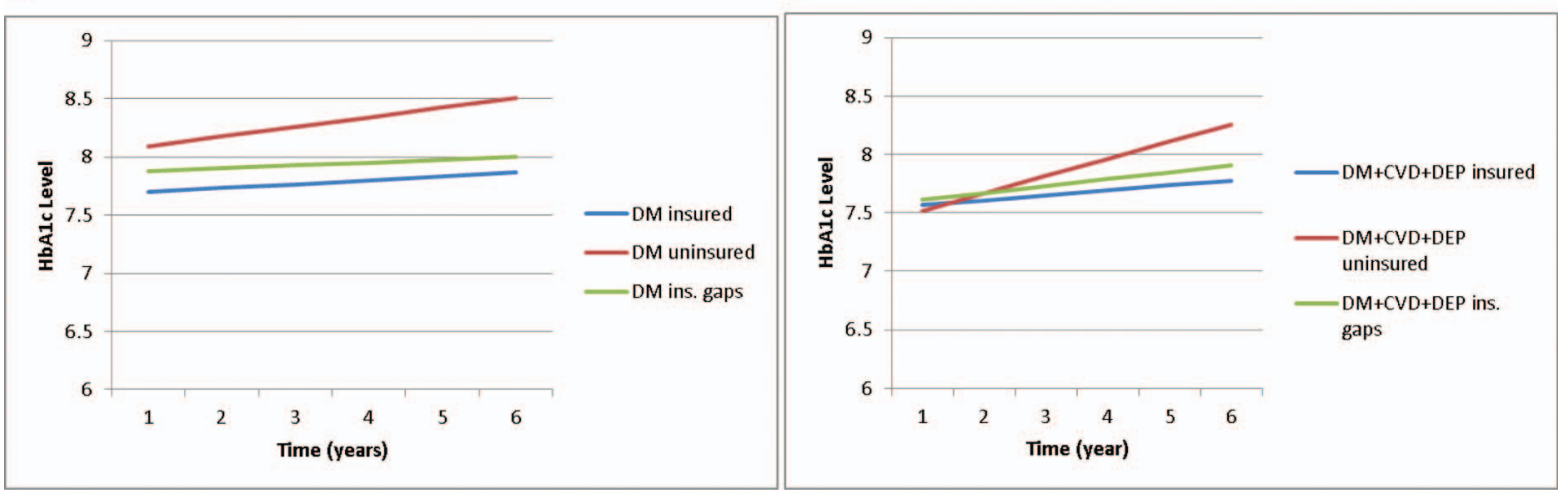
Table 5. Slope Coefficients: Estimated Marginal Mean Differences in Average Change or Slope (Trajectory) of HbA1c Level for Every Unit Change in the Variable*

\begin{tabular}{|c|c|c|c|c|c|}
\hline $\begin{array}{l}\text { Category for Slope } \\
\text { differences for mean } \\
\text { HbAlc }\end{array}$ & Fixed Effects & $\begin{array}{c}\beta \\
\text { Coefficient }\end{array}$ & $\begin{array}{l}\text { SE } \\
(\beta)\end{array}$ & $\begin{array}{c}P \\
\text { Value }\end{array}$ & $\begin{array}{l}\text { Linear Contrast } \\
P \text { Values }\end{array}$ \\
\hline \multirow[t]{4}{*}{ Node } & Grand mean at baseline $^{\dagger}$ & 0.033 & 0.027 & 0.241 & \multirow[t]{4}{*}{$>.500$} \\
\hline & Mean HbA1c level difference, node 2 vs node 1 & -0.006 & 0.021 & 0.795 & \\
\hline & Mean HbA1c level difference, node 3 vs node 1 & 0.015 & 0.040 & 0.723 & \\
\hline & Mean HbA1c level difference, node 4 vs node 1 & 0.006 & 0.017 & 0.711 & \\
\hline Age (at baseline) & Each additional year of age & -0.003 & 0.000 & $<0.001$ & NA \\
\hline Charlson index score & Each additional Charlson index score point & -0.002 & 0.006 & 0.796 & NA \\
\hline Sex & Female vs male & 0.016 & 0.009 & 0.075 & NA \\
\hline \multirow[t]{4}{*}{ Race/ethnicity } & Hispanic vs non-Hispanic white & 0.052 & 0.028 & 0.087 & \multirow[t]{4}{*}{.22} \\
\hline & Non-Hispanic black vs non-Hispanic white & -0.005 & 0.030 & 0.858 & \\
\hline & $\begin{array}{l}\text { Non-Hispanic Asian or Pacific Islander vs non- } \\
\text { Hispanic white }\end{array}$ & -0.014 & 0.023 & 0.559 & \\
\hline & Non-Hispanic other vs non-Hispanic white & -0.052 & 0.047 & 0.284 & \\
\hline \multirow[t]{2}{*}{ Insurance status } & Continually uninsured vs continually insured & 0.054 & 0.021 & 0.024 & \multirow[t]{2}{*}{.014} \\
\hline & Insurance gaps vs continually insured & -0.002 & 0.010 & 0.833 & \\
\hline \multirow[t]{3}{*}{ Primary language } & Spanish vs English & -0.060 & 0.034 & 0.101 & \multirow[t]{3}{*}{.052} \\
\hline & Cantonese or Mandarin vs English & 0.039 & 0.018 & 0.051 & \\
\hline & Other language vs English & 0.019 & 0.027 & 0.479 & \\
\hline \multirow[t]{2}{*}{ Health care use $\mathrm{e}^{\ddagger}$} & 3 or 4 Visits vs 1 or 2 visits & -0.020 & 0.020 & 0.333 & \multirow[t]{2}{*}{$>.500$} \\
\hline & $\geq 5$ Visits vs 1 or 2 visits & -0.024 & 0.021 & 0.280 & \\
\hline
\end{tabular}

*This multilevel model predicted mean HbA1c level as a function of diabetes status, primary language, and insurance status, adjusting for age, Charlson index score, sex, race/ethnicity, and node.

${ }^{\dagger}$ Assuming all other covariates equal zero.

${ }^{\ddagger}$ Average number of annual primary care visits.

NA, not available; SE, standard error.

In addition, the interaction of primary language with DM status was significant for both index date and trajectories of mean HbA1c level. There was a significant Spanish versus English language vector for DM + DEP versus DM-only vector interaction at the index date $(\beta=-0.285 ; P=.008)$ : for patients in the DM + DEP group, those who spoke Spanish as their primary language had a lower HbAlc value at the index date than did those who spoke English as their primary language, but for patients in the DM-only group, the HbAlc value at the index among those who spoke Spanish as their primary language did not seem to differ that of those who spoke English (Figure 3). There was also a significant Spanish versus English language vector for the DM + CVD versus DM-only interaction on the time trajectory $(\beta=-0.171 ; P=.016)$. Among those who spoke Spanish as their primary language, HbA1c declined more over time in the $\mathrm{DM}+\mathrm{CVD}$ group than in the DM-only group. Moreover, among those who spoke English as their primary language, HbA1c level appeared to in- crease more quickly in the DM + CVD group than in the DM-only group; that is, the differential in the positive and negative trajectories over time was larger in the DM + CVD group than in the DMonly group for English and Spanish speakers, respectively.

For both interaction models, coefficient estimates and significance levels of the main effects and adjustor variables remained consistent with those estimated in the base model.

\section{Discussion}

To our knowledge, this is the first published study to examine the relationships among SDHs, DM, CVD, and depression in a large national cohort of safety-net CHC patients. Our results demonstrated that $2 \mathrm{SDH}$ factors, primary language and insurance status, were associated with $\mathrm{HbAlc}$ level among adult patients with at least annual visits to CHCs over a 3 -year period and that these associations varied with disease status, although not always 
Figure 3. Interactions of HbA1c with primary language and diabetes status in the diabetes mellitus [DM]-only group (A), the DM + cardiovascular disease [CVD] group (B), and the DM + CVD + depression [DEP] group (C). Among those for whom Spanish was the primary language, HbA1c declined over time to a greater degree in the DM + CVD (B) group compared to the DM-only group (A). For the DM + CVD + DEP group (C), Spanish speakers had lower baseline HbA1c than English speakers compared with the DM-only group (A), in which a baseline difference was not detected between English and Spanish speakers.

A

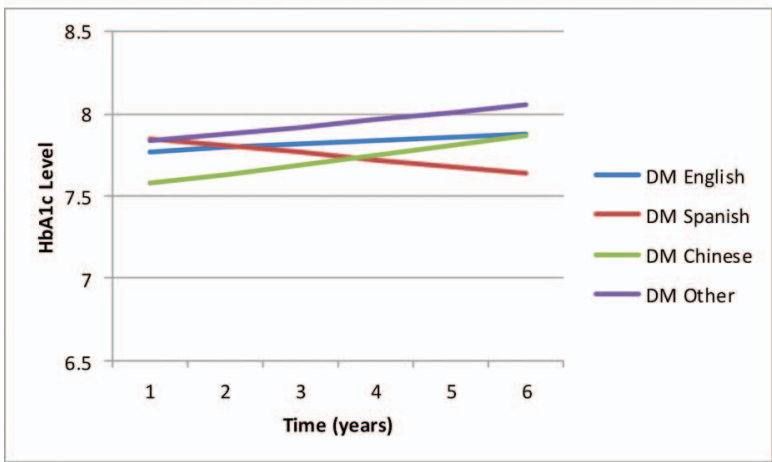

C

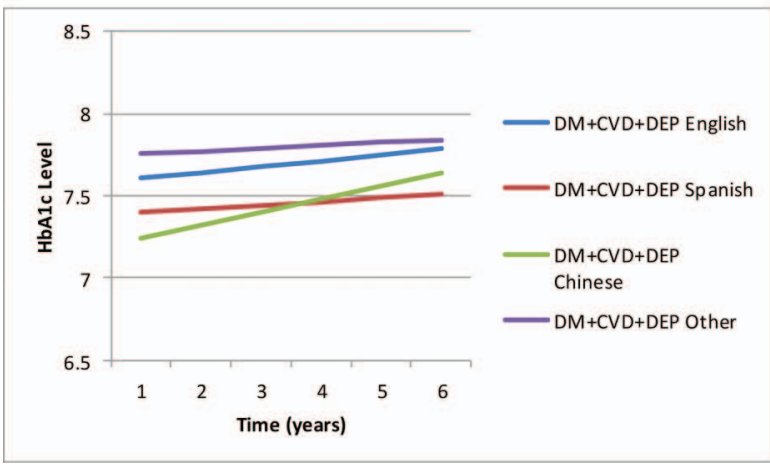

in the directions hypothesized. Our results also indicated that, after accounting for these SDH factors and adjusting for $\mathrm{CHC}$, node, and traditional demographic measures, there was still significant unexplained variability relating to both baseline $\mathrm{HbA1c}$ measures and trajectories.

In this study continuously uninsured patients and those with insurance gaps tended to have higher mean HbA1c levels at the index date, and trajectories over time were steeper in the uninsured group. These results are consistent with other findings suggesting that compared with insured patients, those without insurance tend to have worse access to care, less continuity of care, more unmet needs, and worse outcomes. ${ }^{26,27}$ In our analysis the interaction detected between insurance status and DM status suggests that, in CHC populations, the previous finding may depend to some extent on patients' documented
B

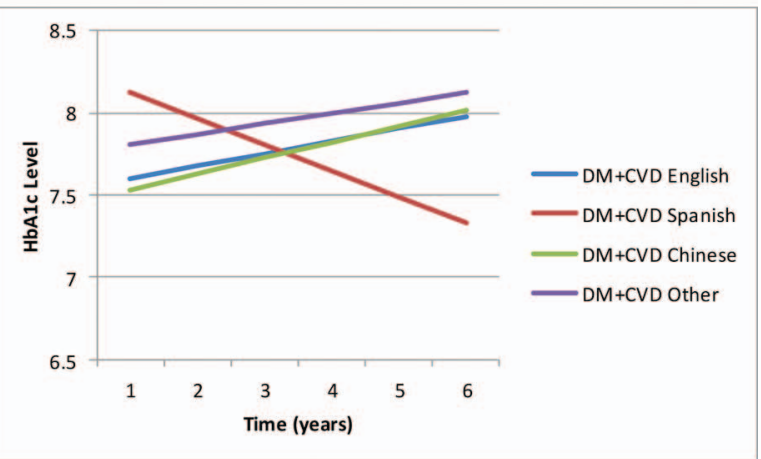

comorbidities. Among patients with DM + DEP, lack of insurance was not associated with index HbA1c level as it was in the DM-only group. One interpretation is that more complex patients are followed more closely by providers regardless of insurance status; these patients may also be more proactive in seeking care and complying with therapy in the CHC setting. Alternatively, it may be that uninsured patients in the DM-only group had greater frequencies of undetected/undocumented comorbid disease (thus not accounted for in the Charlson index score), or had more advanced DM at the index date. Overall, these findings support the notion that continued efforts are needed to identify, describe, and address disparities in and access to insurance coverage.

We detected multiple associations between HbA1c level, primary language, and DM status. 
This is consistent with previous studies that primary language is associated with receipt of recommended health care ${ }^{34,35}$ and that language barriers contribute to health disparities in patients with DM. ${ }^{36}$ Our findings may also reflect the influences of cultural, genetic, or socioeconomic factors and/or health care access (or lack thereof). For example, among Chinese speakers, we saw a lower index HbA1c value and a steeper (positive) trajectory over time. Previous studies indicate that Asian Americans are at higher risk for DM than their white counterparts. ${ }^{37,38}$ Our results may suggest that the trajectory of the disease could potentially be more aggressive in this population, which may warrant more diligent monitoring. Such monitoring could include assessment of medications adherence or cultural perceptions/acceptance regarding available therapies. ${ }^{39}$ Protective associations noted for speakers with limited English proficiency compared with English speakers in the more complex disease groups compared with the DM-only group (ie, HbA1c at the index date in the DM + DEP group and trajectory differential for the DM + CVD group) may reflect more intensive monitoring or increased access to and effectiveness of culturally appropriate enabling services.

We also found some unexpected associations: both groups with depression diagnoses (DM + DEP and DM + CDV + DEP) had a lower HbA1c at the index date compared with the DM-only group; older age was associated with a lower $\mathrm{HbA1c}$ at the index date and a declining trajectory over time; and lower Charlson index scores were associated with steeper increasing trajectories, contradicting earlier studies that higher $\mathrm{HbAlc}$ is associated with depression, ${ }^{40,41}$ older age ${ }^{42}$ and more comorbidities. ${ }^{43}$ Similar findings have been observed previously in CHC settings, ${ }^{44}$ however, and are consistent with $\mathrm{CHC}$ missions of enhanced monitoring and/or health care access for safety-net patients with high comorbidity burdens. CHCs prioritize patients with greater disease complexity and/or more social needs and provide enhanced education and enabling services, as well as outreach, in an effort to ensure that these patients receive appropriate care and take the necessary steps to manage their condition. For example, $\mathrm{CHCs}$ that are recognized as patient-centered medical homes are required to identify a chronic condition for targeted improvement. A CHC patient-centered medical home focusing on DM care coordination may refer patients with $\mathrm{HbA1c}>8 \%$ to care coordination services, which may result in improved health outcomes compared with patients not receiving services. ${ }^{45}$ In addition, more complex patients may have more visits, ${ }^{46}$ providing more opportunities for HbA1c monitoring and intervention, or providers may view controlling $\mathrm{HbA1c}$ as a more urgent priority in patients with multiple comorbidities. Services and treatments received for the comorbidities could also have contributed to the stability of and adherence to DM treatment, even when the use of DM-related services was comparable. ${ }^{47}$ In addition, patients in the more complex DM groups, because of their disease status, could have been receiving more social support from their family, friends, and community, which contributes to better monitoring of their conditions. Another possibility is that, relative to other groups, the DM-only group may have been earlier in the identification/trajectory of disease and therefore less likely to have established stable treatment and monitoring patterns and/or tended to have additional undetected or undocumented health conditions.

\section{Limitations}

Our results should be interpreted with caution because of the observational nature of the study and the variability in EHR documentation/coding practices across multiple systems. In addition, our results relate only to patients who had $\geq 1$ visits for at least 3 consecutive years in a $\mathrm{CHC}$ ambulatory setting. Our results may not apply to patients who do not meet these criteria or who may be more vulnerable to poor health-related outcomes because of more social, clinical, economical, and logistic barriers than the patients studied. In addition, there are likely unmeasured covariates or confounders (including other SDHs) that may influence HbA1c. For example, we were unable to account for potentially important SDHs such as health literacy, housing status, and domestic violence. These unmeasured SDHs could have contributed to some of the unexplained variance in the models. The relationships between the unmeasured SDHs and the SDH variables in this study (insurance status and primary language) may also influence a patient's disease status. In addition, our use of the Charlson index score to adjust for comorbidity burden does not account for conditions that are not predictive of mortality but do affect, for 
example, quality of life or physical functioning. Finally, there were relatively small numbers of patients in certain groups (eg, DM + CVD, DM + CVD + DEP); our results should be confirmed in larger populations. Nevertheless, our study, conducted in a large safety-net population across 17 $\mathrm{CHCs}$, demonstrates the need to better understand the interplay between SDHs, comorbidity burden, and health outcomes in vulnerable patients.

\section{Recommendations and Future Plans}

Improving population health requires collecting and examining data in a more holistic and systematic way that reflects ecosystems of patients' healthrelated risk factors. Understanding the relationship between SDHs and health outcomes is vital to improving outcomes for vulnerable populations facing health inequities. Reimbursement for Medicaid populations is transitioning to global payment models, and there is increasing pressure on $\mathrm{CHC}$ health care practitioners to document needs for enabling services. Evaluating the way SDHs affect health outcomes is critical to appropriately allocate primary care resources to patients who are most at risk and to ensure that resources are allocated to services that are most likely to affect outcomes. Standardized documentation of SDHs and services in the $\mathrm{EHR},{ }^{29}$ including enabling services, ${ }^{48,49}$ is especially important to carry out such evaluations to assess the intermediary role of enabling services in treating complex patients. The data on SDHs can also help in the development of new risk prediction methods that assess the contribution of SDHs to and their impact on health outcomes for all vulnerable populations at CHCs, including both older patients with comorbidities and younger patients with a single disease. By understanding the impact of SDHs on outcomes, CHCs, health plans, and other health care stakeholders can be better informed about SDHs that should be collected and included in predicting outcomes for all patients with any disease trajectory. In addition, using culturally and linguistically appropriate services for patients with limited English proficiency, which are often provided by multilingual and multicultural community health workers at CHCs, can be effective in understanding and addressing patient SDHs, especially for potentially sensitive questions (regarding, for example, incarceration and homeless status).
The goals set by HealthyPeople 2020 include eliminating health disparities and explicitly support improving the social and physical environments of populations. ${ }^{50}$ Collecting data on SDHs and accounting for these factors in analyses will contribute to reaching these goals. Until recently, however, SDHs have not been linked to clinical practice, and SDH data have not been routinely or systematically collected in the medical setting. Recognizing this gap, the Institute of Medicine of the National Academies of Science highlighted the need to integrate SDHs into EHRs to allow for a more holistic and integrated approach to care for all patients ${ }^{51}$ and to facilitate more rigorous research on the causes and consequences of health disparities and the development of interventions and policies to reduce those disparities. Future efforts should prioritize the integration of standardized SDHs into EHR systems. To meet this need, the National Association of Community Health Centers, AAPCHO, Oregon Primary Care Association, and the Institute of Alternative Futures have developed a standardized, national SDH data collection tool that was piloted across CHCs and health center networks, including those participating in CHARN. CHARN is also seeking to expand its data warehouse with additional SDHs so that future analyses will be able to account for the role of SDHs and their relationship to outcomes.

\section{Conclusion}

Insurance status and primary language are $2 \mathrm{SDH}$ that are associated with both index levels and trajectories of $\mathrm{HbAlc}$ in patients with $\mathrm{DM}$ who are receiving health care from a $\mathrm{CHC}$ on a relatively regular basis. In $\mathrm{CHC}$ settings these associations may vary depending on the complexity of disease burden. This study demonstrates the potential power of large, EHR-based data sets to identify patient groups at higher risk for adverse outcomes. Routine EHR documentation and standardization of SDHs, as well as enabling other ancillary services, will provide a more comprehensive understanding of the complex relationships between these measures and disease outcomes.

The authors gratefully acknowledge the following CHARN health centers and research nodes included in the study.

Association of Asian Pacific Community Health Organizations (AAPCHO), San Leandro, CA: Rosy Chang Weir, PhD, 
Vivian Li, MS, Gayathri Rajan, MA, and Morgan Ye; Asian Health Services, Oakland, CA: Thu Quach, PhD, MPH, Masa Tsutsumi, and Simin Kiani; Charles B. Wang Community Health Center, New York, NY: Shao-Chee Sim, PhD, Jennifer D. Lau, Ady Oster, MD, Kai Yeung, and Chihang (Ray) Yu; Waianae Coast Comprehensive Health Center, Waianae, HI: Rachelle Enos, MPH, Vija Sehgal, MD, PhD, MPH, John Williams, BBA, May Okihiro, MD, MS; Waimānalo Health Center, Waimānalo, HI: Mary Frances Oneha, APRN, PhD; University of California, Los Angeles (academic affiliate): Ninez Ponce, MPP, PhD, Marjorie Kagawa-Singer, PhD, MA, $\mathrm{MN}, \mathrm{RN}$, and Ying-Ying Meng, DrPH.

Alliance of Chicago Community Health Services, Chicago, IL: Fred Rachman, MD, Andrew Hamilton, RN, MS, Sarah Rittner, MA, Jessica Park, MPH, CHES, Elizabeth Adetoro, MPH, Anil Chitreddy, and Amro Hassan; Erie Family Health Center, Inc., Chicago, IL: David Buchanan, MD, MS, and Sara Naureckas, MD; Heartland Health Outreach, Chicago, IL: Elizabeth Salisbury Afshar, MD, MPH, and Caroline Thurlow, MD; Howard Brown Health Center, Chicago, IL: Magda Houlberg, MD, Kristin Keglovitz Baker, MS, and John Stryker, NP; Near North Community Health Center, Chicago, IL: Timothy Long, MD; North Country HealthCare, Flagstaff, AZ: Anne Newland, MD; PCC Community Wellness, Chicago, IL: Marge Altergott, $\mathrm{PhD}$; Northwestern University, Chicago, IL (academic affiliate): Stephen Per sell, MD, MPH, Melissa Simon, MD, MPH, and Brian Hitsman, PhD.

Fenway Health, Boston, MA: Ken Mayer, MD, Chris Grasso, MPH, and Lydia Dant, MPH; Chase Brexton Health Care, Baltimore, MD: Sebastian Ruhs, MD, Amina Chaudhry, MD, MPH, and Mensah Amuzu; Beaufort-Jasper-Hampton Comprehensive Health Services, Ridgeland, SC: Monica Godfrey, $\mathrm{MPH}$, and Jeff Ratzel; University of Washington, Seattle (academic affiliate): Heidi Crane, MD, MPH, Bill Lober, MD, MS, Justin McReynolds, and Dana King, ALM.

OCHIN, Inc., Portland, OR: Christine Nelson, PhD, RN, Jon Puro, MPA-HA, Melissa Laurie, MPH, and Jennifer DeVoe, MD, DPhil; Open Door Community Health Centers, Arcata, CA: Joseph Carroll, MD, PhD; Virginia Garcia Memorial Health Centers, Hillsboro, OR: Ann Turner, MD, and Christian Hill, MD, MPH; Multnomah County Health Department, Portland, OR: Paul Denouden, MD; Oregon Health \& Science University, Portland (academic affiliate): Erika Cottrell, PhD, MPP, Steffani Bailey, PhD, Robert Schuff, MS, and John Saultz, MD; Richmond Family Medicine Clinic, Portland, OR: John Muench, MD, MPH.

Data coordinating center, Kaiser Permanente, Center for Health Research, Portland, OR: Mary Ann McBurnie, PhD, Steve Fortmann, MD, Michael Leo, PhD, Reesa Laws, BS, Phil Crawford, MS, Suzanne Gillespie, MS, Celeste Machen, Kelly Kirk, MS, Meredith Vandermeer, MPH, and Chalinya Ingphakorn.

\section{References}

1. Commission on Social Determinants of Health. Closing the gap in a generation: health equity through action on the social determinants of health.
CSDH final report. Geneva: World Health Organization; 2008. Available from: http://www.who.int/ social_determinants/thecommission/finalreport/en/. Accessed March 28, 2016.

2. Marmot M, Bell R. Fair society, healthy lives. Public Health. 2012;126(Suppl 1):S4-10.

3. Braveman P, Egerter S, Williams DR. The social determinants of health: coming of age. Annu Rev Public Health 2011;32:381-98.

4. Adler NE, Stewart J, eds. The biology of disadvantage: socioeconomic status and health. New York: John Wiley \& Sons; 2010.

5. Braveman P, Gottlieb L. The social determinants of health: it's time to consider the causes of the causes. Public Health Rep 2014;129(Suppl 2):19-31.

6. Braveman PA, Egerter SA, Woolf SH, Marks JS. when do we know enough to recommend action on the social determinants of health? Am J Prev Med 2011;40(1 Suppl 1):S58-66.

7. McGinnis JM, Foege WH. Actual causes of death in the United States. JAMA 1993;270:2207-12.

8. Marmot M, Wilkinson R, eds. Social determinants of health. 2nd ed. Oxford: Oxford University Press; 2006.

9. Hurt LS, Ronsmans C, Saha S. Effects of education and other socioeconomic factors on middle age mortality in rural Bangladesh. J Epidemiol Community Health 2004;58:315-20.

10. Crimmins EM, Saito Y. Trends in healthy life expectancy in the United States, 1970-1990: gender, racial, and educational differences. Soc Sci Med 2001;52:1629-41.

11. Farmer P. Infections and inequalities. Berkeley: University of California Press; 1999.

12. Druss BG, Reisinger Walker E. Mental disorders and medical comorbidity. Research synthesis report no. 21. Hoboken, NJ: The Robert Wood Johnson Foundation; 2011. Available from: http://www.rwjf. org/content/dam/farm/legacy-parents/mental-disorders-and-medical-comorbidity. Accessed March 28, 2016.

13. Lorant V, Deliège D, Eaton $W$, Robert A, Philippot $\mathrm{P}$, Ansseau M. Socioeconomic inequalities in depression: a meta-analysis. Am J Epidemiol 2003;157:98112 .

14. Lett HS, Blumenthal JA, Babyak MA, Strauman TJ, Robins C, Sherwood A. Social support and coronary heart disease: epidemiologic evidence and implications for treatment. Psychosom Med 2005;67:869-78.

15. National Association of Community Health Centers (NACHC). America's health centers. Bethesda, MD: NACHC; 2013. Available from: http://www.nachc. com/client/documents/USHealthCentersFS.pdf. Accessed April 15, 2016.

16. Shin P, Alvarez C, Sharac J, Rosenbaum S, Van Vleet A, Paradise J, Garfield R. A profile of community health center patients: implications for policy. Menlo Park, CA: Henry J. Kaiser Family Founda- 
tion; 2013. Available from: http://kff.org/medicaid/ issue-brief/a-profile-of-community-health-centerpatients-implications-for-policy/. Accessed March 28, 2016.

17. Chang Weir R, Law H, Frances Oneha M, Lee SM, Chien AT. Impact of a P4P and HIT program to reduce emergency department hospital utilization at federally qualified health centers in Hawai'i. AAPI Nexus Policy Pract Community 2014;12(1-2):8396.

18. de Groot M, Anderson R, Freedland KE, Clouse RE, Lustman PJ. Association of depression and diabetes complications: a meta-analysis. Psychosom Med 2001;63:619-30.

19. Park M, Katon WJ, Wolf FM. Depression and risk of mortality in individuals with diabetes: a metaanalysis and systematic review. Gen Hosp Psychiatry 2013;35:217-25.

20. Sturm R. The effects of obesity, smoking, and drinking on medical problems and costs. Health Aff (Milwood) 2002;21:245-53.

21. Hansen MS, Fink P, Frydenberg M, Oxhøj ML. Use of health services, mental illness, and self-rated disability and health in medical inpatients. Psychosom Med 2002;4:668-75.

22. Li V, Chang Weir R, Quach T, et al. Building a community health center data warehouse to promote patient-centered research in the Asian American, Native Hawaiian, and Pacific Islanders population. AAPI Nexus Policy Pract Community 2014;12(1-2):.

23. Green AR, Ngo-Metzger Q, Legedza ATR, Massagli MP, Phillips RS, Iezzoni LI. Interpreter services, language concordance, and health care quality: experiences of Asian Americans with limited English proficiency. J Gen Intern Med 2005;20:1050-6.

24. Gandhi TK, Burstin HR, Cook EF, et al. Drug complications in outpatients. J Gen Intern Med 2000;15:149-54.

25. Jacobs EA, Shepard DS, Suaya JA, Stone EL. Overcoming language barriers in health care: costs and benefits of interpreter services. Am J Public Health 2004;94:866-9.

26. Agency for Healthcare Research and Quality. 2012 National healthcare disparities report. Rockville, MD: Agency for Healthcare Research and Quality; 2013.

27. Centers for Disease Control and Prevention. Vital signs: health insurance coverage and health care utilization-United States, 2006-2009 and JanuaryMarch 2010. MMWR Morb Mortal Wkly Rep 2010; 59:1448-54.

28. American Diabetes Association. Diagnosis and classification of diabetes mellitus. Diabetes Care 2010; 33(Suppl 1):S62-9.

29. Laws R, Gillespie S, Puro J, et al. The Community Health Applied Research Network (CHARN) data warehouse: a resource for patient-centered out- comes research and quality improvement in underserved, safety net populations. EGEMS (Wash DC) 2014;2:1097.

30. Deyo R, Cherkin DC, Ciol MA. Adapting a clinical comorbidity index for use with ICD-9-CM administrative databases. J Clin Epidemiol. 1992;45:613-9.

31. Bryk AS, Raudenbush SW. Hierarchical linear models: applications and data analysis methods. 2nd ed. Thousand Oaks, CA: Sage Publications; 2002.

32. Hox J. Multilevel analysis: techniques and applications. 2nd ed. New York: Routledge; 2010.

33. Snijders T, Bosker R. Multilevel analysis: an introduction to basic and advanced multilevel modeling. Thousand Oaks, CA: Sage; 1999.

34. Cheng E, Chen A, Cunningham W. Primary language and receipt of recommended health care among Hispanics in the United States. J Gen Intern Med 2007;22(Suppl 2)283-8.

35. Clough J, Lee S, Chae DH. Barriers to health care among Asian immigrants in the United States: a traditional review. J Health Care Poor Underserved 2013;24: 384-403.

36. Fernandez A, Schillinger D, Warton M, et al. Language barriers, physician-patient language concordance, and glycemic control among insured Latinos with diabetes: the Diabetes Study of Northern California (DISTANCE). J Gen Intern Med 2011;26: 170-6.

37. Lee JW, Brancati F, Yeh HC. Trends in the prevalence of type 2 diabetes in Asians versus whites: results from the United States National Health Interview Survey, 1997-2008. Diabetes Care 2011;34: 353-7.

38. Maskarinec G, Jacobs S, Morimoto Y, Chock M, Grandinetti A, Kolonel LN. Disparity in diabetes risk across native Hawaiians and different Asian groups: the multiethnic cohort. Asia Pac J Public Health 2015;27:375-84.

39. Leung AY, Ai Bo A, Hsiao HY, Wang SS, Chi I. Health literacy issues in the care of Chinese American immigrants with diabetes: a qualitative study. BMJ Open 2014;4:e005294.

40. Hassan K, Loar R, Anderson BJ, Heptulla RA. The role of socioeconomic status, depression, quality of life, and glycemic control in type 1 diabetes mellitus. J Pediatr 2006;149:526-31.

41. Lustman PJ, Clouse RE. Depression in diabetic patients: the relationship between mood and glycemic control. J Diabetes Complications 2005;19:113-22.

42. Kirkman MS, Briscoe VJ, Clark N, et al. Diabetes in older adults. Diabetes Care 2012;35:2650-64.

43. Ahern MM, Hendryx M. Avoidable hospitalizations for diabetes: comorbidity risks. Dis Manag 2007;10: 347-55.

44. Quach T, Gilmer TP, Hirota S, Ponce NA. Risk adjustment with social determinants of health and implications for federally qualified health centers un- 
der the Affordable Care Act. AAPI Nexus Policy Practice Community 2014;12:73-82.

45. Chang Weir R, Emerson HP, Tseng W, Chin M, Caballero J. Utilization of enabling services by Asian American, Native Hawaiian, and Pacific Islander patients at community health centers. Am J Public Health 2010;100:2199-205.

46. Dixon LB, Kreyenbuhl JA, Dickerson FB, et al. A comparison of type 2 diabetes outcomes among persons with and without severe mental illnesses. Psychiatr Serv 2004;55:892-900.

47. Struijs JN, Baan CA, Schellevis FG, Westert GP, AM van den Bos G. Comorbidity in Patients with Diabetes Mellitus: Impact on Medical Health Care Utilization. BMC Health Services Research. 2006; 6:84 doi:10.1186/1472-6963-6-84.

48. Enabling services data collection implementation packet. San Leandro, CA: Association of Asian Pacific Community Health Organizations; 2016. Available from: http://www.aapcho.org/resources_db/ enabling-services-data-collection-implementationpacket/. Accessed March 28, 2016.

49. Chang Weir R, Proser M. Highlighting the role of enabling services at community health centers: collecting data to support service expansion and enhanced funding. San Leandro, CA: Association of Asian Pacific Community Health Organizations; 2010. Available from: http://www.aapcho.org/ resources_db/highlighting-the-role-of-enablingservices-at-community-health-centers/. Accessed March 28, 2016.

50. Centers for Disease Control and Prevention (CDC). Leading health indicators development and framework. Available from: http://www.healthypeople.gov/ 2020/leading-health-indicators/Leading-HealthIndicators-Development-and-Framework. Accessed March 28, 2016.

51. Institute of Medicine. Capturing social and behavioral domains in electronic health records: phase 1. Washington, DC: National Academies Press; 2014. 